\title{
Article \\ Nicotinic Acetylcholine Receptor Subunit $\alpha 7$ Mediates Cigarette Smoke-Induced PD-L1 Expression in Human Bronchial Epithelial Cells
}

\author{
Hoi-Hin Kwok ${ }^{1} \mathbb{D}$, Boning Gao ${ }^{2}$, Koon-Ho Chan ${ }^{1}$, Mary Sau-Man Ip ${ }^{1}$, John Dorrance Minna ${ }^{2}$ \\ and David Chi-Leung Lam ${ }^{1, * \mathbb{D}}$
}

1 Department of Medicine, Li Ka Shing Faculty of Medicine, The University of Hong Kong, Hong Kong, China; kwokh@hku.hk (H.-H.K.); koonho@hku.hk (K.-H.C.); msmip@hku.hk (M.S.-M.I.)

2 Hamon Center for Therapeutic Oncology Research, University of Texas Southwestern Medical Center, Dallas, TX 75390, USA; boning.gao@utsouthwestern.edu (B.G.); john.minna@utsouthwestern.edu (J.D.M.)

* Correspondence: dcllam@hku.hk; Tel.: +852-2255-4455

\section{check for} updates

Citation: Kwok, H.-H.; Gao, B.; Chan, K.-H.; Ip, M.S.-M.; Minna, J.D.; Lam, D.C.-L. Nicotinic Acetylcholine Receptor Subunit $\alpha 7$ Mediates Cigarette Smoke-Induced PD-L1 Expression in Human Bronchial Epithelial Cells. Cancers 2021, 13, 5345. https://doi.org/10.3390/ cancers13215345

Academic Editors: Rajkumar Savai and Michael Thomas

Received: 27 September 2021

Accepted: 22 October 2021

Published: 25 October 2021

Publisher's Note: MDPI stays neutral with regard to jurisdictional claims in published maps and institutional affiliations.

Copyright: (c) 2021 by the authors. Licensee MDPI, Basel, Switzerland. This article is an open access article distributed under the terms and conditions of the Creative Commons Attribution (CC BY) license (https:/ / creativecommons.org/licenses/by/ $4.0 /)$.
Simple Summary: Lung cancer is strongly associated with tobacco smoking. Nicotine in tobacco smoke can be transformed into a carcinogen after in vivo metabolism. However, the mechanism of how nicotine metabolites modulate a pro-tumorigenic microenvironment remains largely unknown. We have explored the effects of nicotine stimulation on nicotinic acetylcholine receptor subunit alpha 7 (nAChR $\alpha 7$ )-mediated PD-L1 expression in human bronchial epithelial cells (HBECs). PD-L1 is an important protein contributing to cancer immune escape and is currently the key biomarker for lung cancer immunotherapy. Here, we found that the nicotine metabolite NNK can induce PD-L1 expression in HBECs by acting through the nicotine receptor $\mathrm{nAChR} \alpha 7$. This study has a direct impact on the understanding of smoking-related changes in bronchial epithelial cells and potential immune escape in smoking-related carcinogenesis and has immuno-therapeutic implications via PD-L1 in lung cancer. Further studies are warranted to examine the upstream inhibition of PD-L1-related pathways, which could be mediated through nicotinic acetylcholine receptors in smokers, and may ultimately aid in the prevention and treatment of lung cancer.

Abstract: Tobacco smoking is the top risk factor for lung cancer development. Nicotine in cigarettes can induce addiction, and its derivatives become potent carcinogens after metabolic activation and activate oncogenic signaling in lung epithelial cells through their expressed nicotinic acetylcholine receptors (nAChRs). However, the effects of smoking on the tumor immune microenvironment are under investigation. In the current study, we investigated whether nicotine activation of nicotinic acetylcholine receptor subunit $\alpha 7$ (nAChR $\alpha 7, C H R N A 7)$ would induce PD-L1 expression in lung epithelial cells. The expression levels of $n A C h R \alpha 7$ and PD-L1 in eight human bronchial epithelial cell (HBEC) lines were measured after treatment with cigarette smoke extract (CSE) or nicotine derivatives. The results showed that PD-L1 expression levels increased in HBECs after exposure to CSE or nicotine derivatives. This induction of PD-L1 expression could be diminished by treatment with CHRNA7 small-interfering RNA, and the relevant signaling was mediated via STAT3 phosphorylation and NRF2 expression. In summary, this study demonstrated that the well-known nicotine derivative-activated $n A C h R \alpha 7$ could induce STAT3/NRF2 pathways and subsequently promote PD-L1 expression in normal lung epithelial cells. This information provides mechanistic insight into cigarette smoke-induced immune evasion in lung epithelial cells.

Keywords: lung cancer; cigarette smoke; PD-L1; CHRNA7; bronchial epithelial cells

\section{Introduction}

Tobacco smoking is the top risk factor for the development of nearly all types of lung cancer. Among the different histological subtypes of lung cancer [1], squamous 
cell carcinoma (SCC) is strongly associated with tobacco smoking [2]. Many different types of carcinogens are found in cigarette smoke. While nicotine itself is not considered to be directly carcinogenic, addiction to nicotine is the major factor driving cigarette smoking and thus exposure to tobacco carcinogens. In addition, nicotine can be converted to 4-(methylnitrosoamino)-1-(3-pyridyl)-1-butanone (NNK), which is a potent carcinogen from metabolic activation. This role is demonstrated by how potent NNK is in inducing lung tumor development in animal models [3]. As part of this, NNK metabolites bind to DNA, forming DNA adducts which can result in genetic mutations.

In previous genome-wide association studies (GWASs), genetic polymorphisms in chromosome region 15q25 were found to be associated with increased risk of developing lung cancer. This $15 \mathrm{q} 25$ region harbors three nicotinic acetylcholine receptor (nAChR) subunit genes, namely CHRNA3, CHRNA4, and CHRNA5 [4]. These genetic variants may affect nicotine dependence, leading to greater exposure or susceptibility to carcinogens in cigarette smoke and hence increased risk of lung cancer development [5]. In fact, CHRNA7 (located at 15q13.3) gene duplication was found to increase lung cancer risk [6]. In addition, several studies showed that lung epithelial cells and lung cancer can express nAChRs and that nicotine at concentrations found in smokers can bind to these receptors and activate signaling mechanisms that could play a role in lung cancer pathogenesis [7]. These include studies that showed that cigarette smoking can act through $\mathrm{nAChR} \alpha 7$ to modulate inflammatory responses [8]. All these studies suggested that nicotine-based ligand-activated $\mathrm{nAChR}$ and its downstream signaling aberrations may contribute to lung cancer development.

The use of immune checkpoint inhibitor/blockade (ICB) therapy has emerged as an important treatment strategy for NSCLC in recent years. The best treatment response was shown in patients with high tumor expression levels of programmed death receptor ligand-1 (PD-L1), usually with a tumor proportional score (TPS, \% of tumor cells expressing PD-L1) above $50 \%$. Smokers with lung cancer are usually seen to derive more benefit from immune checkpoint therapy compared to non-smokers with lung cancer [9]. Smoking status was significantly associated with tumor mutation burden [10] and with higher tumor PD-L1 expression [11] in lung cancer. However, the correlation of PD-L1 expression and tumor mutation burden with clinical benefit from ICB is yet to be determined. There is also consideration of employing ICB to intercept pre-neoplastic lesions. The molecular mechanisms regulating PD-L1 expression in lung cancer and the tumor microenvironment are being explored, and recent functional genomic approaches have identified several unexpected mechanisms [12]. Our previous studies demonstrated that nicotine could stimulate CHRNA7 expression in human bronchial epithelial cells (HBECs) and that HBECs could be used to study the pathogenesis of lung cancer through defined genetic manipulations $[7,13]$. The aim of this study was to test whether nicotine and cigarette smoke extract (CSE) could act through defined $n A C h R \alpha 7$ to influence the expression of PD-L1 in HBECs.

\section{Materials and Methods}

\subsection{In Silico Gene Expression Analysis}

Gene expression data of different $C H R N$ subunit genes in normal lung were downloaded from Genotype-Tissue Expression (GTEx). Differential expression analysis of CHRN subunit genes between normal and lung tumor lungs was performed using Lung Cancer Explorer [14] and UALCAN [15].

\subsection{Cell Culture}

Eight immortalized human bronchial epithelial cell (HBEC) lines were used. These cell lines were established from bronchial biopsies obtained during diagnostic bronchoscopy. HKBS62N-KT, HKBS65.2N-KT, HKBS160N-KT, and HKBS189N-KT were derived from smokers; HKBS150N-KT, HKBS197N-KT, HKBS198N-KT, and HKBS202.5N-KT were derived from non-smokers. Bronchial specimens from local non-cancer patients were obtained with informed consent. These subjects had bronchoscopy with autofluorescence 
imaging performed, and the bronchial biopsies were all confirmed histologically to be nonneoplastic [7]. In bronchoscopy with autofluorescence imaging (AFI), suspicious areas will show up as areas of magenta fluorescence color, in contrast to the green fluorescence color for normal bronchial epithelium. Bronchial biopsies of the normal green fluorescence color were cultured and immortalized to become cell lines used in this study. Immortalization of HBECs was performed according to the previously published protocol [16]. These cells were cultured in keratinocyte-serum-free medium and were treated with cigarette smoke extract (CSE, aqueous extract of two Marlboro cigarettes (12 $\mathrm{mg}$ tar, $1 \mathrm{mg}$ nicotine) bubbled into $20 \mathrm{~mL}$ PBS, $0.22 \mu \mathrm{m}$ filtered) [17] or NNK (\#N-076, Sigma-Aldrich, St. Louis MO, USA) (5 or $10 \mu \mathrm{M})$ [18] in supplement-free medium as previously described [19].

\subsection{RNA Extraction and Quantitation of mRNA Expression}

Total RNA was extracted from HBECs using an RNAeasy mini extraction kit (\#74106, Qiagen, Hilden, Germany). Complementary DNA was synthesized with the QuantiTect reverse transcription kit (\#205311, Qiagen, Germany). The expression level of the target genes was determined by quantitative real-time PCR using the QuantiTect SYBR Green PCR kit (\#204143, Qiagen, Germany). All the reactions were performed with a LightCycler480 II real-time PCR machine (Roche Diagnostics, Penzberg, Germany). The relative expression levels of CHRNA7 subunit genes were normalized to the expression levels of GAPDH. The sequences of primers used were as follows: CHRNA7-F, 5'-AGC CAG CAA TTC TGA GTT CTG-3'; CHRNA7-R, 5'-TTG CCC ATC TCC AGT GAA TC-3'; CD274-F, 5'- GGC ATC CAA GAT ACA AAC TCA AAG-3'; CD274-R, 5'-CTT CCT CTT GTC ACG CTC AG-3'; GAPDH-F, 5'-GTC AGT GGT GGA CCT GAC CT-3'; GAPDH-R, 5'-TGA GCT TGA CAA AGT GGT CG-3'.

\subsection{Protein Extraction and Immunoblot Analysis}

Whole cell protein was extracted using RIPA buffer (\#89900, Thermo Fisher, San Jose, CA, USA) supplemented with protease and phosphatase inhibitor (\#A32959, Thermo Fisher, San Jose, CA, USA). The protein concentration of the cell lysate was determined by protein assay (\#5000006, Bio-Rad, Hercules, CA, USA). Protein samples were separated by $10 \%$ SDSPAGE and blotted onto nitrocellulose membranes (\#1228243, Santa Cruz Biotechnology, Santa Cruz, CA, USA). The membranes were then incubated in blocking buffer ( $5 \%$ non-fat dry milk in TBS-T) and subsequently in diluted primary antibodies against specific targets at $4{ }^{\circ} \mathrm{C}$ overnight. The membranes were then washed and incubated with horseradish peroxidase-conjugated goat anti-rabbit or goat anti-mouse secondary antibody (\#7074 and \#7076, Cell Signaling Technology, Cell Signaling Technology, Danvers, MA, USA). Immunoreactive bands were visualized by ECL Western blotting reagents (\#RPN2106, GE Healthcare, Chalfont St Giles, IJ, UK). Primary antibodies, including anti-nAChR $\alpha 7$ (\#sc-5544, 1:500, Santa Cruz Biotechnology, USA), anti-PD-L1 (\#sc-50298, 1:500, Santa Cruz Biotechnology, USA), anti-STAT3 (\#9139, 1:1000, Cell Signaling Technology, USA), anti-phospho-STAT3 (Y705) (\#9145, 1:500, Cell Signaling Technology, USA), anti-NRF2 (\#16396-1-AP, 1:500, Proteintech, Rosemont, IL, USA), and HRP-conjugated anti-GAPDH (\#HRP-60004, 1:2000, Proteintech, USA), were used in the immunoblot analysis.

\subsection{Immunofluorescence Microscopy}

HBECs $\left(1 \times 10^{4}\right.$ cells / well) were plated onto a 96-well cell culture plate overnight. After NNK treatment, cells were fixed in cold paraformaldehyde $(4 \%, w / v)$ at room temperature for $15 \mathrm{~min}$. After washing with PBS three times, cells were incubated in blocking reagent (1\% BSA in PBS) for one hour and then in primary anti-PD-L1 (\#sc-50298, 1:200, Santa Cruz Biotechnology, USA) antibody at $4{ }^{\circ} \mathrm{C}$ overnight. Cells were washed with PBS and then incubated with Alexa Fluor 488-conjugated goat anti-rabbit secondary antibody (\#A-11008, 1:500, Thermo Fisher, USA) at room temperature for one hour. Nuclei were counter-stained with DAPI $(0.5 \mu \mathrm{g} / \mathrm{mL})$. Plates were washed with PBS three times, and fluorescence images were acquired using the ImageXpress Pico Automated 
Cell Imaging System (Molecular Devices, Union City, CA, USA) with a $10 \times$ objective lens. Positive cell-integrated intensities were used to compare the fluorescence images from different treatments.

\subsection{Transient Transfection of Small Interfering RNA (siRNA)}

HBECs at $60 \%$ confluence were transiently transfected with CHRNA7-specific siRNA (\#S103054443, FlexiTube siRNA) or non-targeting control siRNA (\#1027281, AllStars Negative Control) $(20 \mathrm{nM})$ obtained from Qiagen. Cells were treated with an RNA-lipofectamine complex (Lipofectamine 3000, \#L3000015, Thermo Fisher, USA) in supplement-free medium for $24 \mathrm{~h}$ followed by NNK treatment.

\subsection{Cignal 45-Pathway Reporter Arrays}

Cignal 45-pathway reporter arrays were used according to the manufacturer's protocol. Briefly, 96-well plates coated with designated reporter plasmids were mixed with transfection reagent (Lipofectamine 3000, \#L3000015, Thermo Fisher, USA). HBECs transfected with siRNA $\left(1 \times 10^{4}\right.$ cells/well $)$ were then transferred to the 96 -well plates. The transfection medium was removed after $24 \mathrm{~h}$, and cells were then treated with NNK $(10 \mu \mathrm{M})$ for another $24 \mathrm{~h}$. Luciferase activity was detected using a dual-luciferase reporter assay system (\#E1960, Promega, Madison, WA, USA). The luminescence signal was then measured using a microplate reader (CLARIOstar BMG Labtech, Ortenberg, Germany). The firefly luciferase activity was normalized by the Renilla luciferase activity in each well.

\subsection{Statistical Analyses}

CHRNA7 levels are reported as mean \pm standard deviation. Comparisons between different treatment groups were analyzed by either chi-square tests or Student's $t$-tests. Multiple group comparisons were conducted with one-way ANOVA followed by Tukey's post hoc analyses. GraphPad Prism version 6.01 (GraphPad Software Inc., La Jolla, CA, USA) was used for all statistical analyses. A two-sided $p$-value of less than 0.05 was considered statistically significant.

\section{Results}

\subsection{CHRNA7 Expression Is Associated with Lung Cancer}

The in silico gene expression analysis showed that CHRNA5 and CHRNA7 were the two most highly expressed CHRN subunit genes in the normal lung tissues (Figure 1A). Moreover, CHRNA7 was overexpressed in lungs with cancer compared to non-cancerinvolved "normal" lungs by over 30\% (Figure 1B, upper panel). CHRNA7 expression levels were also higher in smokers than in non-smokers (Figure 1B, lower panel). In fact, the higher expression of CHRNA7 in lung squamous cell carcinoma was associated with poor survival in the TCGA-LUSC cohort (Figure 1C).

\section{2. nAChR R-Mediated Smoking-Induced PD-L1 Expression in HBECs}

Both CSE and NNK were found to be able to induce CHRNA7 and PD-L1 (CD274) mRNA expression in HBECs derived from both smokers and non-smokers (Figure 2A). Furthermore, the immunoblot analysis showed that NNK could induce nAChR $\alpha 7$ and PD-L1 protein expression in HBECs (Figures 2B and S2) and their expression on the cell surface by immunofluorescence staining (Figure 2C).

To determine if $\mathrm{NNK}$ was acting through $\mathrm{nAChR} \alpha 7$ to induce PD-L1 expression, we used siRNA-mediated knockdown of CHRNA7 (Figure 3A). We saw that the inducing effects of NNK on PD-L1 mRNA (Figure 3B) and protein (Figures 3C and S2) expression were abolished by CHRNA7 knockdown in HBECs established from both smokers and non-smokers. This supports the role of $n A C h R \alpha 7$ as a key mediator for NNK-induced PD-L1 expression. 
A

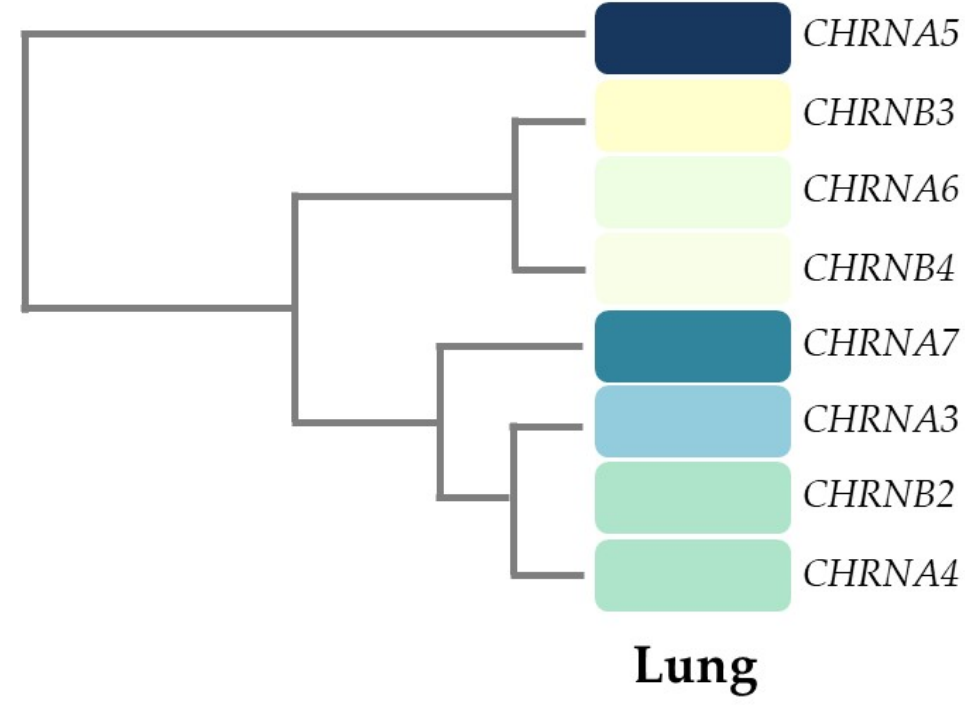

$\begin{array}{lllllll}\text { Transcript } & 0.0 & 0.040 & 0.082 & 0.13 & 0.17 & 0.22\end{array}$

Per Million

B
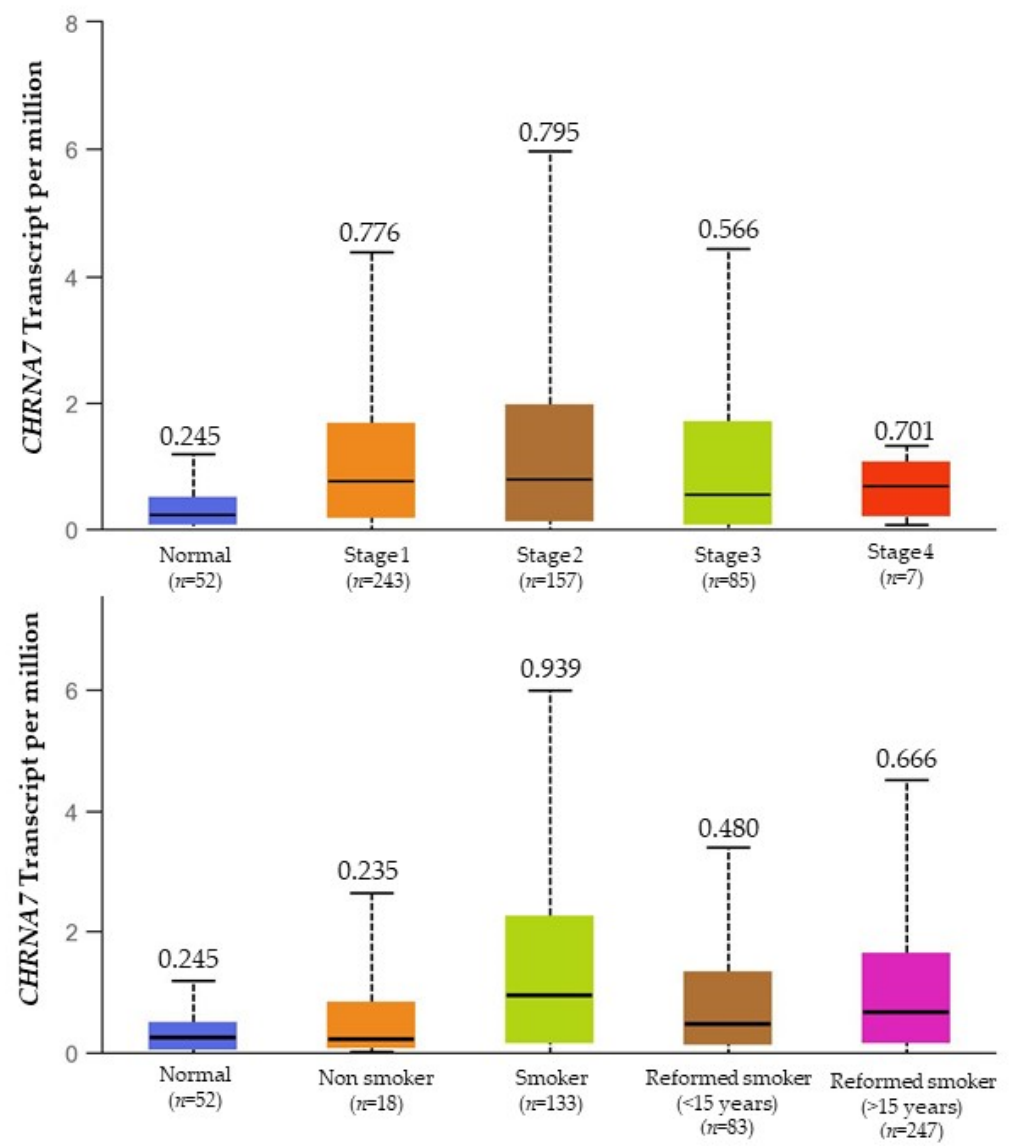

Figure 1. Cont. 


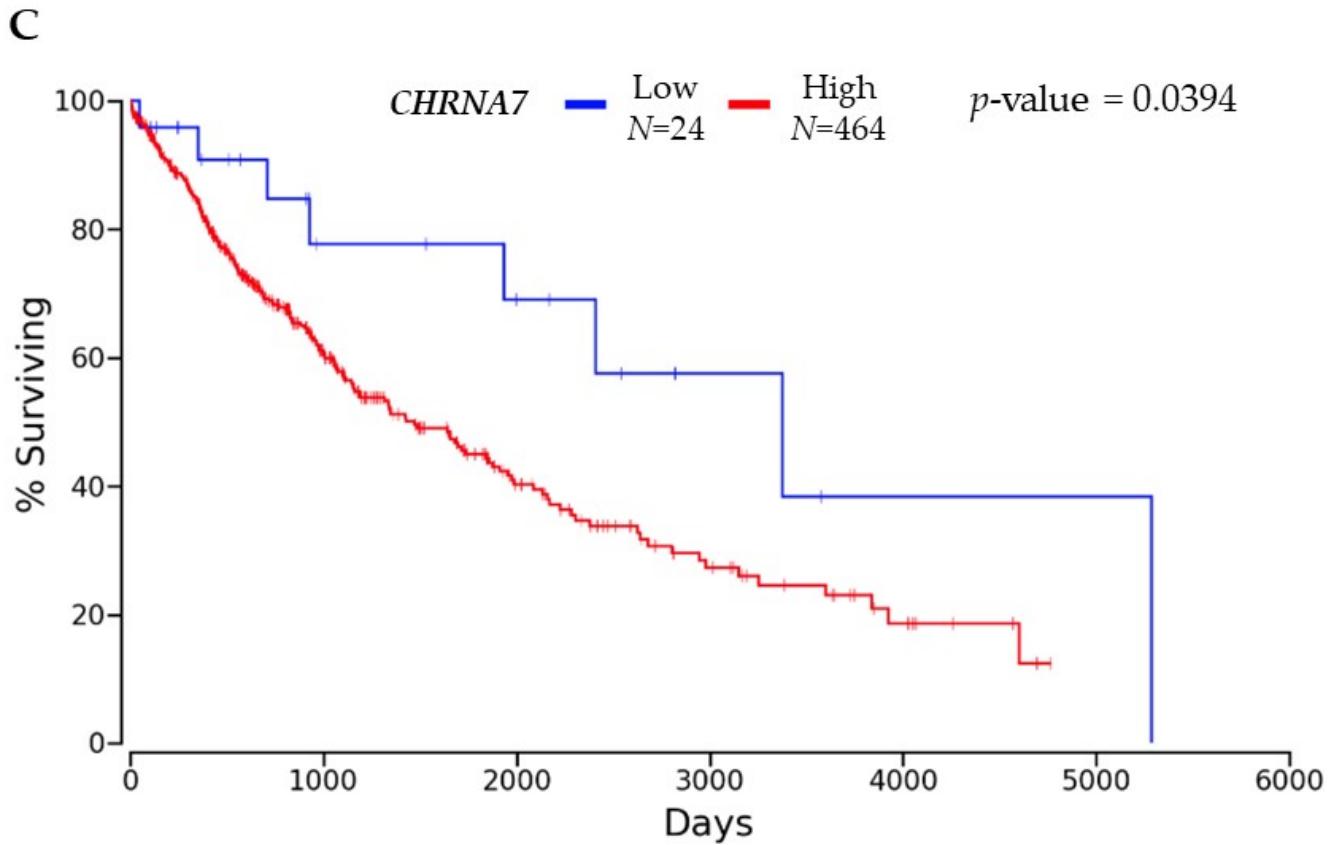

Figure 1. CHRNA7 expression and clinicopathological correlations in TCGA-LUSC cohort. (A) Expression levels of CHRN subunit genes in normal lung from GTEx portal. (B) Boxplots of CHRNA7 gene expression comparing normal lung tissues against different stages of lung cancer (upper panel), or non-smoking patients against patients with different smoking habits (lower panel) in the TCGALUSC dataset; median of each bar is shown. (C) Kaplan-Meier analysis of lung squamous cell carcinoma patients in the TCGA-LUSC cohort (Oncolnc).

\subsection{Antioxidant and STAT3 Pathways Were Involved in Mediating $n A C h R \alpha 7-R e g u l a t e d$ PD-L1 Expression}

To explore the mechanisms by which $\mathrm{nAChR} \alpha 7$ regulates PD-L1 expression, we performed promoter activity screening assays with the Cignal 45-pathway reporter array. To obtain NNK acting through nAChR $\alpha 7$ receptor-specific effects, we compared Cignal45pathway reporter activity (luciferase activity) under four conditions: pathway activity after treatment with a non-CHRNA7-targeting siRNA (baseline activity after siRNA treatment); the same non-targeting siRNA but with NNK (activity seen with NNK acting through the receptor); specific knockdown of CHRNA7 expression with a targeted siRNA without NNK; and knockdown of CHRNA7 with NNK treatment (Supplementary Figure S1). These studies showed that NNK specifically acts through $\mathrm{nAChR} \alpha 7$, activated DNA damage, MYC, Wnt, NFE2L2-antioxidant response elements, STAT3, and some other signaling pathways (Supplementary Figure S1). Knockdown of CHRNA7 reversed some of these activations, particularly the NFE2L2-antioxidant response and STAT3 signaling pathways (Figure 4A), suggesting the involvement of the two pathways in NNK-induced PD-L1 expression $[20,21]$. 
A
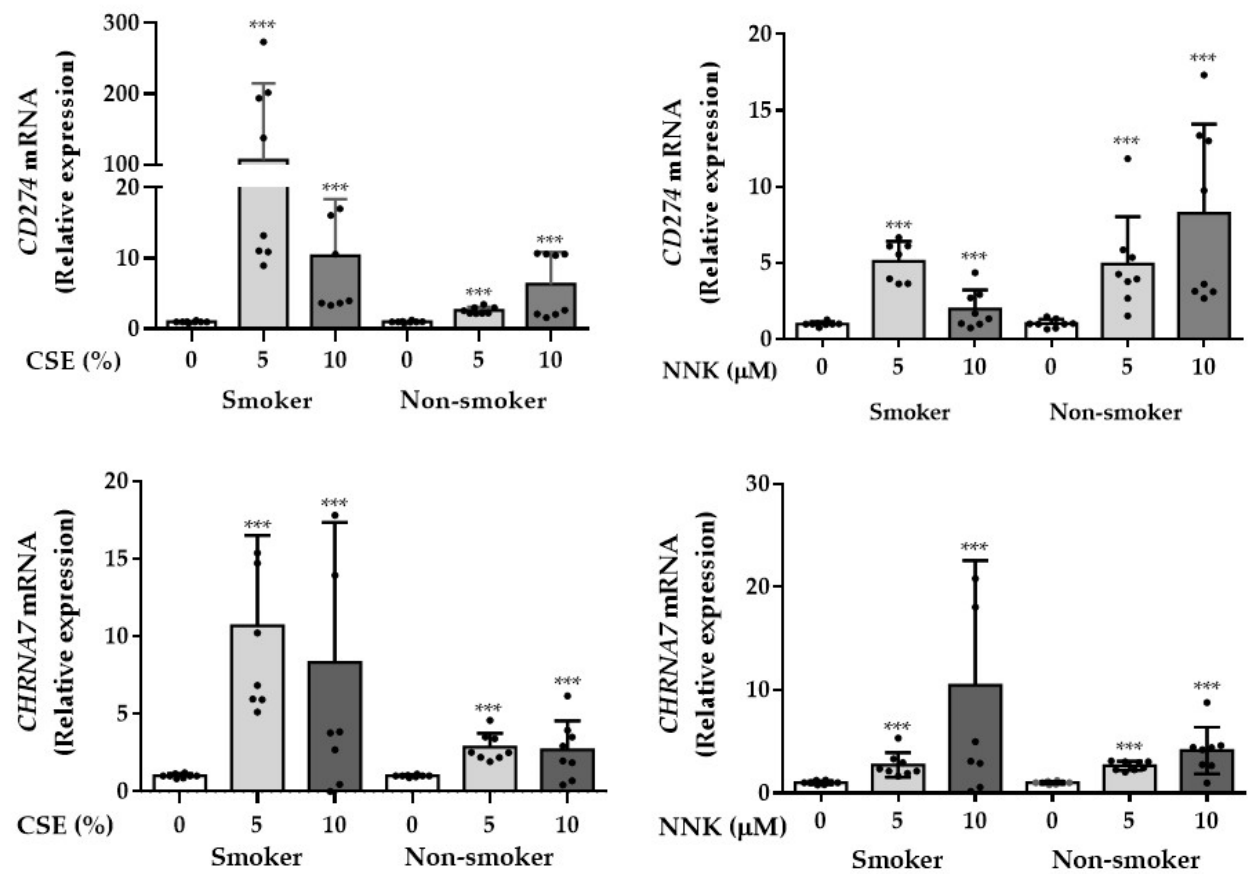

B
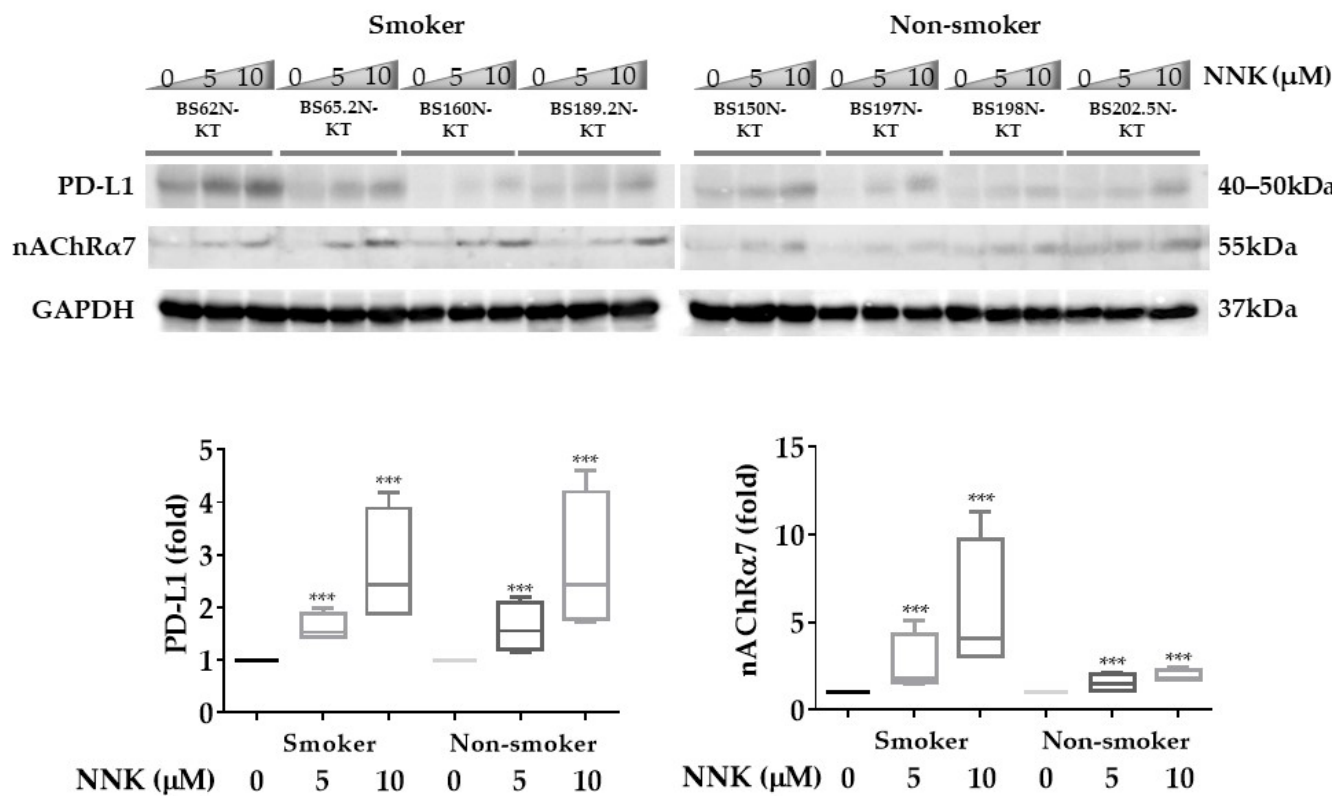

Figure 2. Cont. 


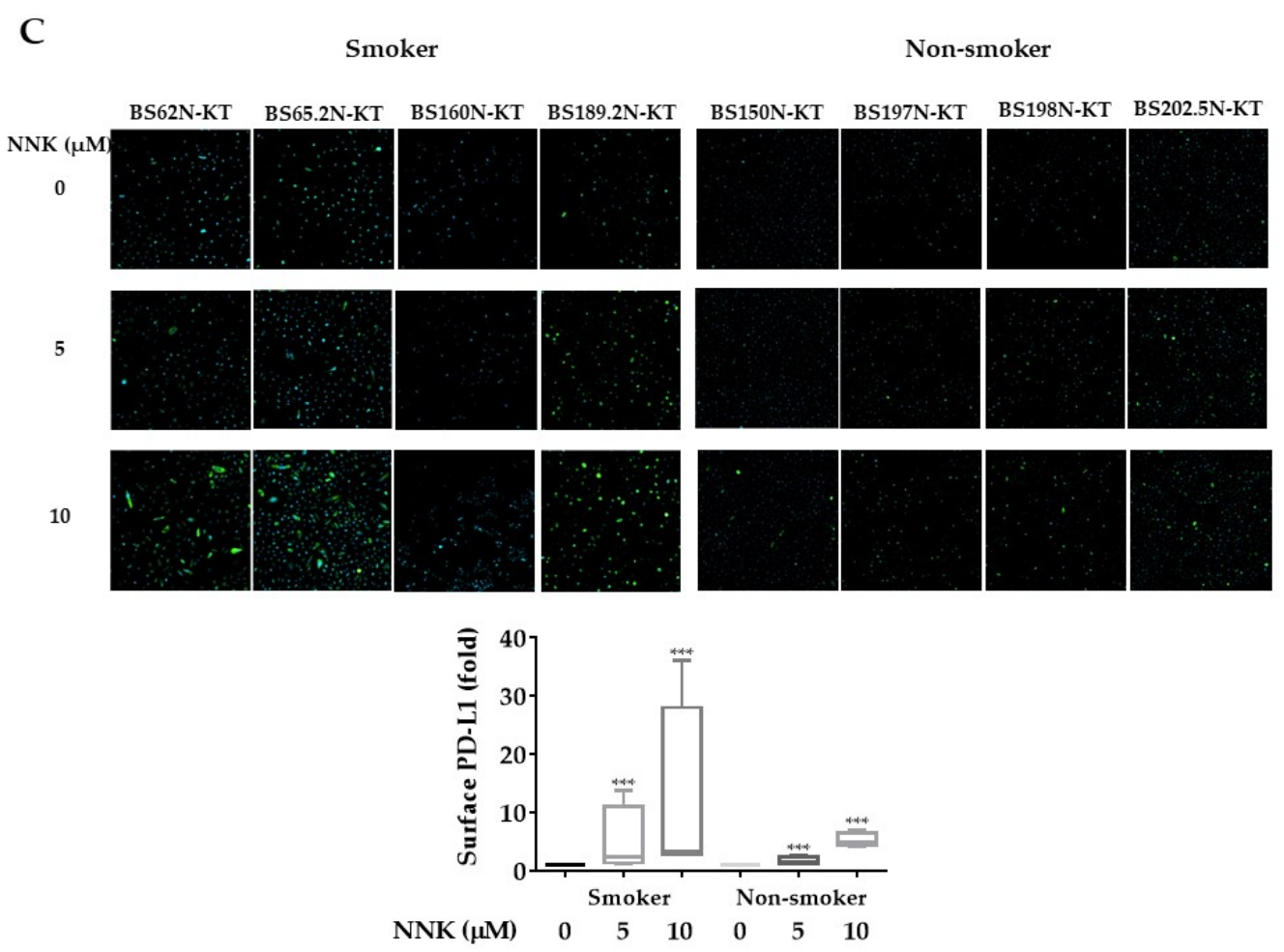

Figure 2. Cigarette smoke and the carcinogen NNK induce PD-L1 expression on human bronchial epithelial cells (HBECs). HBECs derived from smokers (BS62N-KT, BS65.2N-KT, BS160N-KT, and BS189.2N-KT) or non-smokers (BS150N-KT, BS197N-KT, BS198N-KT, and BS202.5N-KT) were exposed to cigarette smoke extract (CSE, 5 or $10 \%$ ) or NNK ( 5 or $10 \mu \mathrm{M})$ for $48 \mathrm{~h}$, and CD274 and CHRNA7 (A) mRNA expression was measured by real-time RT-PCR; (B) PD-L1 and nAChR $\alpha 7$ protein expression was determined by Western blot analysis; (C) surface PD-L1 expression was measured by immunofluorescence staining. The values are presented as mean \pm S.D. from technical triplicate experiments. ${ }^{* * *} p<0.001$.

A

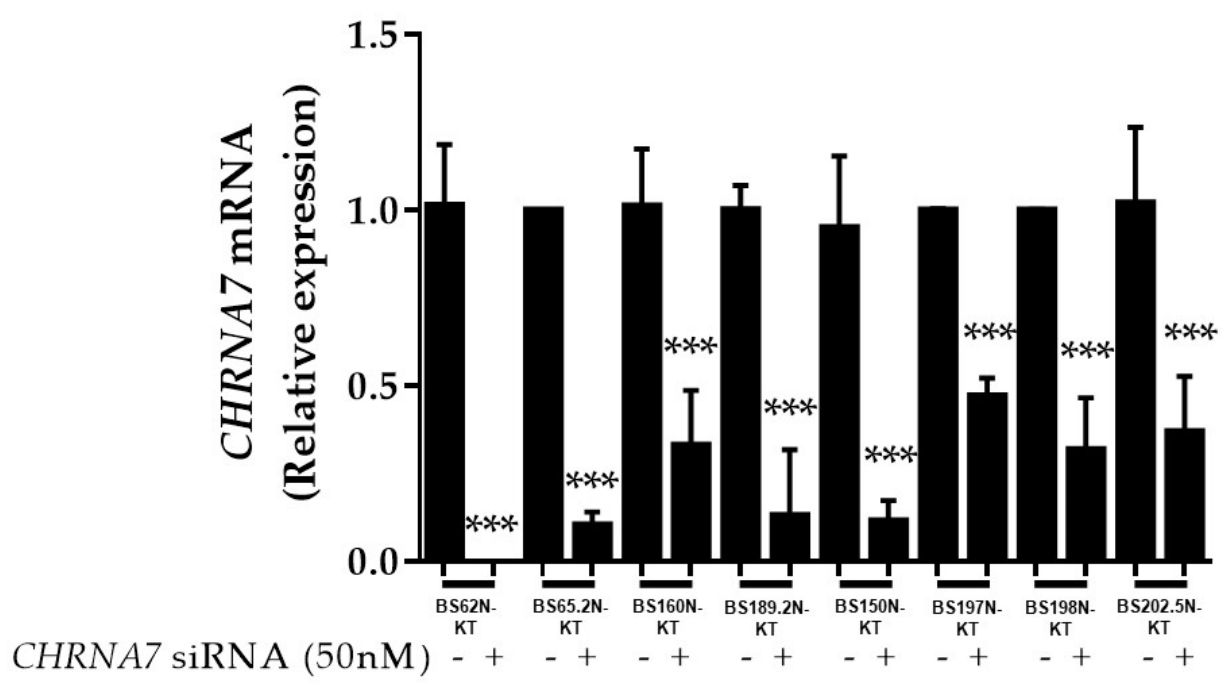

Figure 3. Cont. 
B
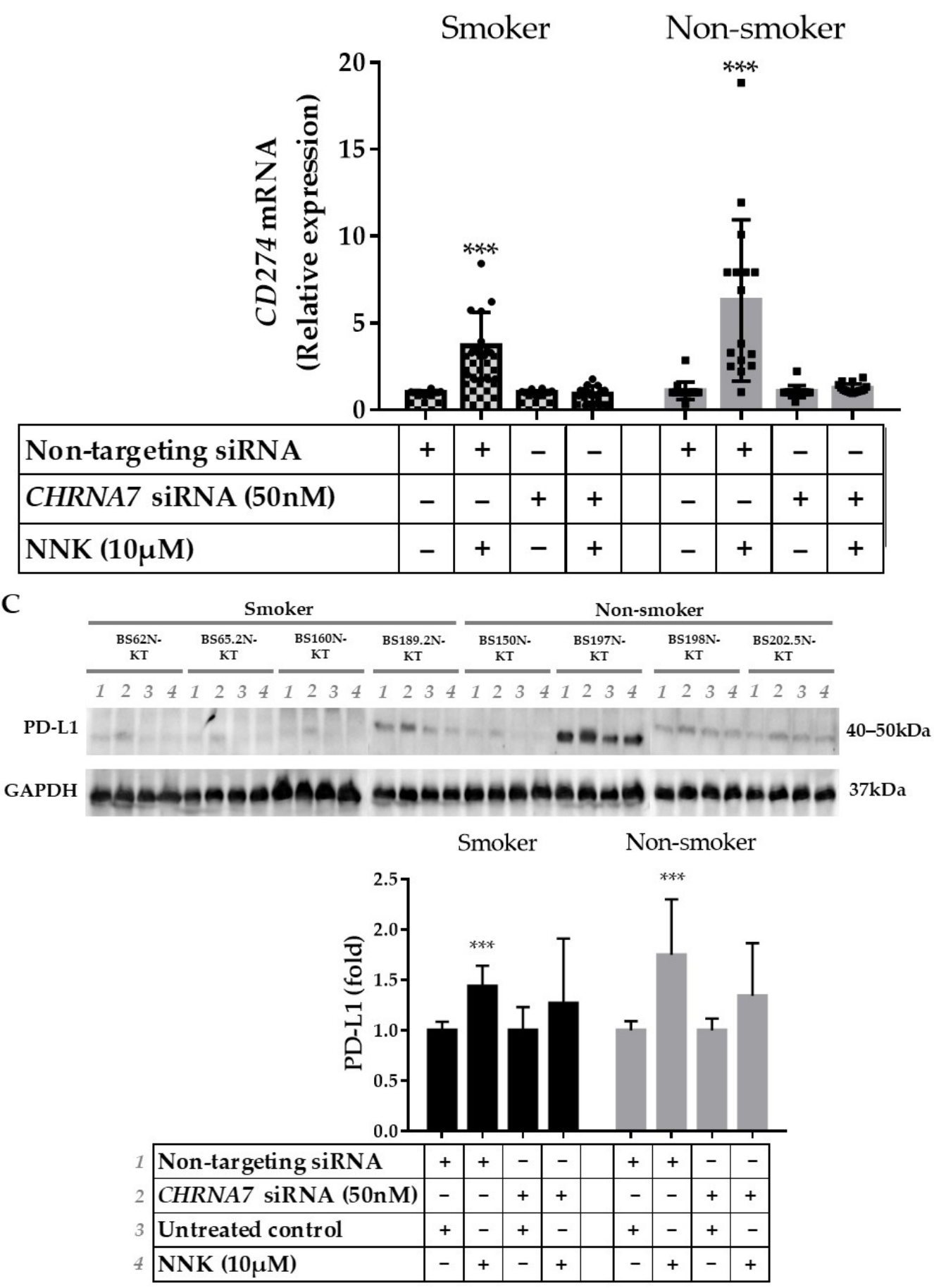

Figure 3. $\mathrm{nAChR} \alpha 7$-mediated NNK-induced PD-L1 expression. (A) HBECs were treated with nontargeting or CHRNA7-specific siRNA ( $50 \mathrm{nM}$ ) for $24 \mathrm{~h}$, and the expression of CHRNA7 mRNA was measured by real-time RT-PCR. HBECs with or without knockdown of CHRNA7 by siRNA (50 nM) for $24 \mathrm{~h}$ were further treated with NNK $(10 \mu \mathrm{M})$ for another $48 \mathrm{~h}$; the expression of CD274 (PD-L1) (B) mRNA expression was measured by real-time RT-PCR; (C) protein expression was determined by Western blot analysis. The values are presented as mean \pm S.D. from technical triplicate experiments. *** $p<0.001$. 
To investigate the roles of the NRF2 and STAT3 signaling pathways, Western blot analysis was performed to evaluate the induction or activation of NRF2 and STAT3 following NNK exposure. NNK treatment induced NRF2 protein expression and STAT3 phosphorylation in the two HBEC cell lines (Figures 4B and S2), while siRNA-mediated CHRNA7 knockdown abolished these effects. In addition, we pharmacologically confirmed that NRF2 and STAT3 were downstream mediators of NNK-induced PD-L1 expression by pretreating two HBECs with either the STAT3 inhibitor (C188-9) or the NRF2 inhibitor (ML385) prior to NNK treatment. Both inhibitors suppressed NNK-induced PD-L1 expression (Figures $4 \mathrm{C}$ and S2) in the HBECs.

A
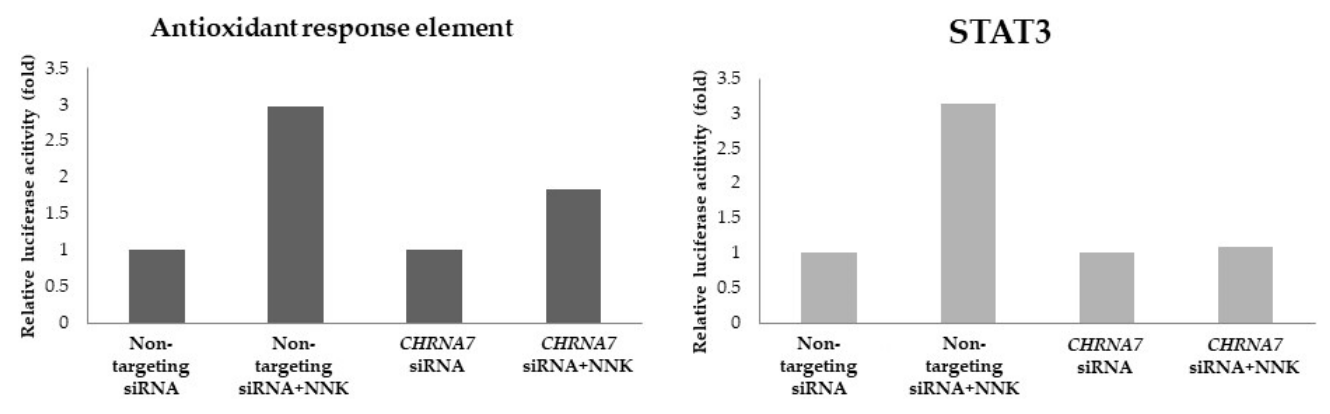

B

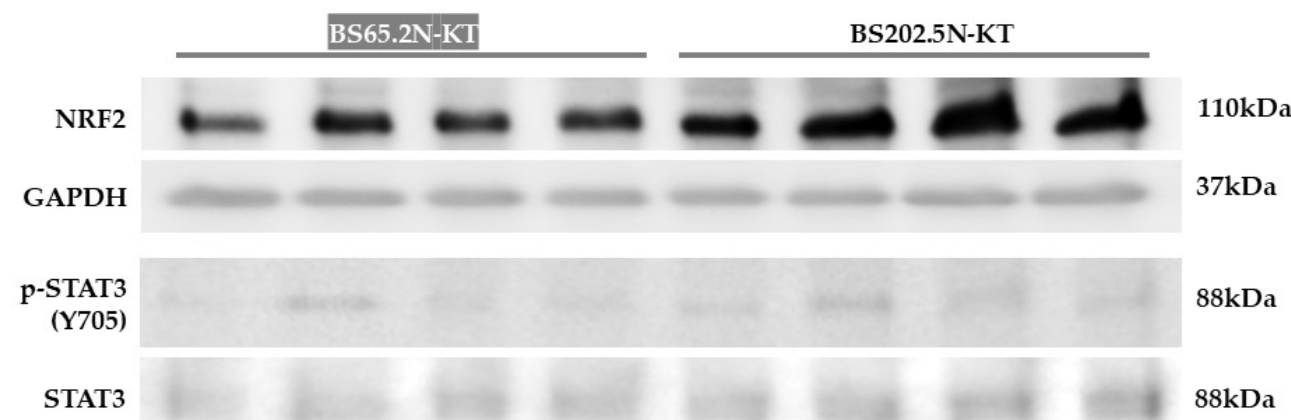

\begin{tabular}{|c|c|c|c|c|c|c|c|c|}
\hline $\begin{array}{l}\text { Non-targeting } \\
\text { siRNA (50nM) }\end{array}$ & + & + & - & - & + & + & - & - \\
\hline $\begin{array}{l}\text { CHRNA7 siRNA } \\
(50 \mathrm{nM})\end{array}$ & - & - & + & + & - & - & + & + \\
\hline NNK $(10 \mu \mathrm{M})$ & - & + & - & + & - & + & - & + \\
\hline
\end{tabular}
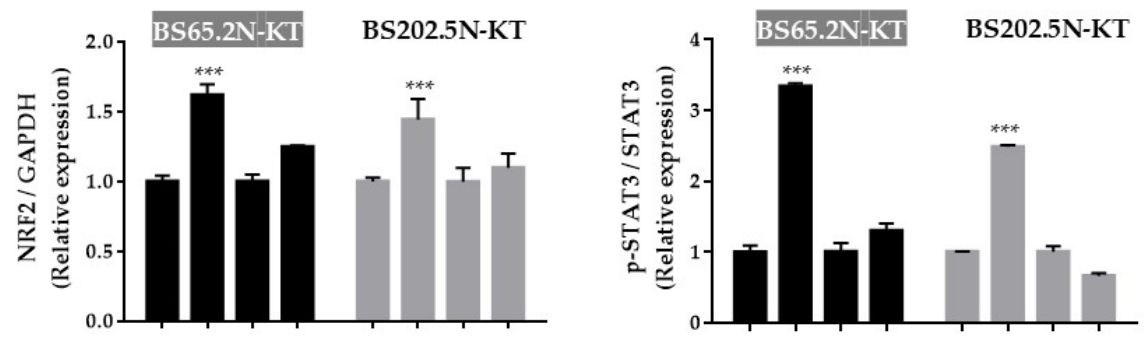

Figure 4. Cont. 
C

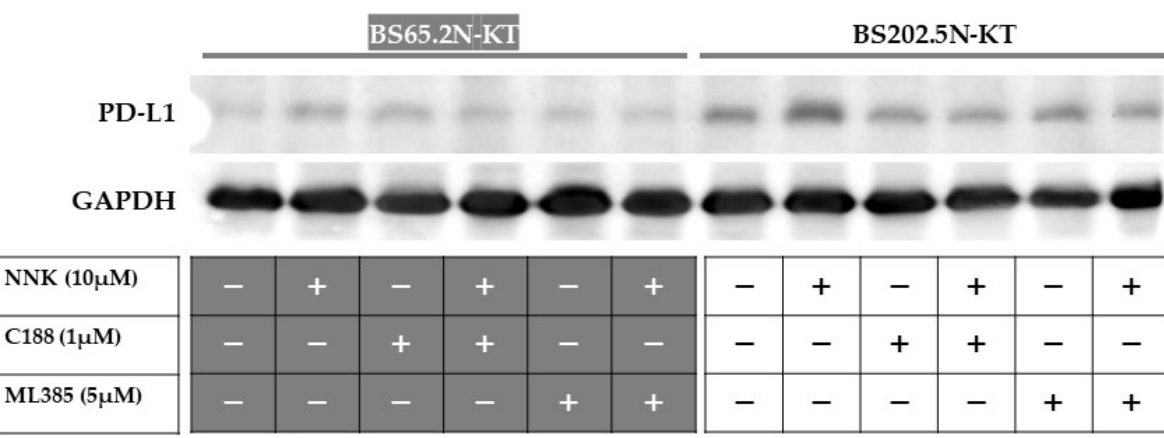

$40-50 \mathrm{kDa}$

$37 \mathrm{kDa}$

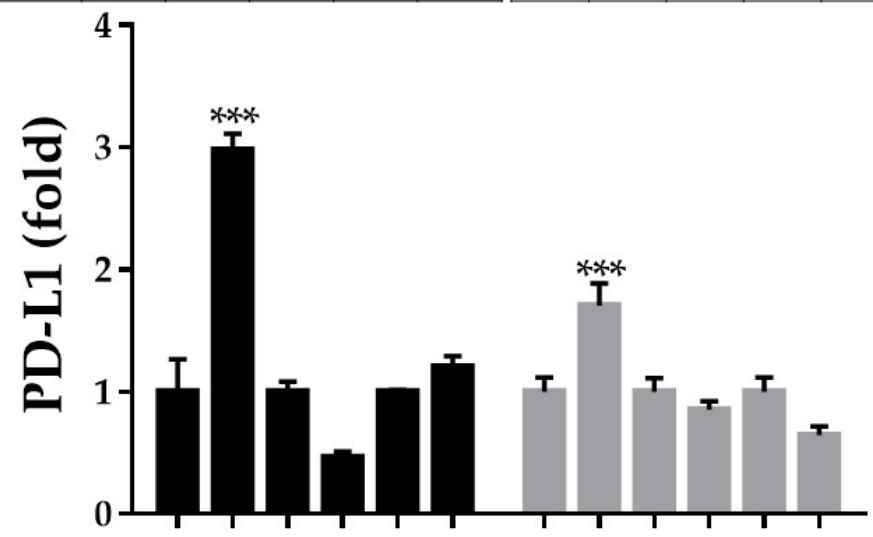

Figure 4. nAChR $\alpha 7$-mediated NNK-induced PD-L1 expression through NRF2 and STAT3 signaling. (A) HBECs transfected with non-targeting or CHRNA7-targeting siRNA (50 nM) for $24 \mathrm{~h}$ were seeded on the assay plate of a Cignal 45-pathway reporter array and then reverse-transfected with reporter plasmids. Cells were then treated with NNK $(10 \mu \mathrm{M})$ for another $24 \mathrm{~h}$. Firefly and Renilla luciferase activities were measured. Normalized luciferase activities were compared with those of non-NNKtreated cells. Representative pathways are shown. (B) HBECs were treated with non-targeting or CHRNA7-targeting siRNA $(50 \mathrm{nM})$ for $24 \mathrm{~h}$ and then treated with NNK $(10 \mu \mathrm{M})$ for another $48 \mathrm{~h}$. The expression of NRF2 and STAT3 phosphorylation was measured with Western blot analysis. (C) HBEC s were co-treated with NNK $(10 \mu \mathrm{M})$ and the STAT3 inhibitor C188 $(1 \mu \mathrm{M})$ or the NRF2 inhibitor ML385 $(5 \mu \mathrm{M})$ for $48 \mathrm{~h}$. PD-L1 protein expression levels were determined by Western blot analysis. The values are presented as mean \pm S.D. from technical triplicate experiments. ${ }^{* *} p<0.001$.

\section{Discussion}

By treating HBEC strains derived from different individuals with NNK, combined with studies on the expression and functional genomic knockdown of CHRNA7, we found that exposure of HBECs to CSE or NNK acting through $\mathrm{nAChR} \alpha 7$ leads to significantly increased expression of PD-L1 on HBECs. In addition, we have provided evidence that this involves signaling through STAT3/NRF2. These findings provide a mechanism for the observed increased PD-L1 expression in bronchial epithelial tissues and SCC from smokers. The effects of CHRNA7 knockdown on PD-L1 expression may also identify a chemopreventive opportunity to counteract the carcinogenic effects of tobacco smoking even after smoking cessation.

Recent studies suggested that different chemical substances, such as polycyclic aromatic hydrocarbons, aldehydes, various volatile hydrocarbons [22], and nicotine, which may also be present in electronic cigarette smoke could contribute to lung carcinogenesis [14]. It has been well demonstrated that nicotine derivatives, including NNK and NNN, can induce the formation of DNA adducts and initiate carcinogenesis. Nicotine and its derivatives can also bind with nAChRs and induce various aberrant cellular signaling processes involved in tumorigenesis. The in silico analysis (Figure 1) also suggested that smoking may induce higher expression of $n A C h R \alpha 7$, which may contribute to cancer development via unknown mechanisms. Studies in different cancers suggested that PD-L1 
expression was up-regulated in pre-malignant lesions [23,24], and early PD-L1 blockade may prevent cancer development [25]. However, whether nicotine and its derivatives could contribute to pre-malignant immune invasion through PD-L1 expression remained unknown. In this study, we confirmed the involvement of $\mathrm{nAChR} \alpha 7$ mediation in nicotine derivative-induced PD-L1 expression in HBECs.

$\mathrm{nAChR} \alpha 7$ is widely expressed in neuronal tissue, the digestive tract, and in the lungs and the airways; plays various roles in smoking-related schizophrenia [26] and chronic pulmonary diseases [6]; and is also associated with higher angiotensin-converting enzyme II (ACE-2) expression and subsequent higher risk of severe COVID-19 infection [27,28]. It is known that $\mathrm{nAChR} \alpha 7$-mediated signaling is involved in the regulation of various tumorigenic processes [29]. In melanoma, it has been shown that nicotine could induce PD-L1 expression via CHRNA9 and could promote cell proliferation and migration [30]. However, our study demonstrated, for the first time, a direct mediating role of $n A C h R \alpha 7$ in smoking-induced PD-L1 expression in normal lung epithelial cells.

Transcriptional regulation of PD-L1 has been shown to be activated by various intrinsic oncogenic pathways. Cancer cells utilize interferon-activated JAK-STAT-IRF1 proinflammatory signaling to induce PD-L1 expression in cancer cells [31]. Moreover, dysregulation of NRF2 could directly [32] or indirectly [33] increase PD-L1 expression levels. Cigarette smoke affects multiple intracellular responses in bronchial epithelial cells, including the above-mentioned pathways (Figure 4A). Nicotinic activation of CHRNA7 promoted the phosphorylation of STAT3 and NRF2 expression (Figure $4 B, C$ ), which may synergistically promote the transcription of PD-L1. Previous studies suggested that smoking or oncogenes could induce persistent activation or overexpression of NRF2, which may in turn contribute to lung tumorigenesis [20,21]. Our study demonstrated the link of nAChR $\alpha$ 7-activated STAT3/NRF2 pathways with downstream PD-L1 expression.

PD-L1 expression in normal tissues is tightly regulated by multiple signaling pathways to maintain immune homeostasis. Wang et al. previously demonstrated that benzo $(\alpha)$ pyrene from tobacco could induce PD-L1 expression in HBECs via the induction of aryl hydrocarbon receptor (AhR) [34]. The results of this study further support that various carcinogenic components in cigarette smoke may contribute to increased PD-L1 expression in normal bronchial epithelial cells. Gene Set Enrichment Analysis and Ingenuity Pathway Analysis on lung squamous cell carcinoma suggested a more pro-inflammatory phenotype in heavy smokers [35]. This may further promote pre-cancerous immune evasion, which may ultimately lead to cancer formation. Indeed, there are several ongoing clinical trials to investigate the possibility of prevention of malignant transformation by treating high-risk smokers with a PD-L1 inhibitor. Further studies are warranted to examine the upstream inhibition of PD-L1-related pathways, which could be mediated through nicotinic acetylcholine receptors in smokers. However, direct systemic administration of most nicotinic acetylcholine receptor antagonists can cause a variety of side effects due to the lack of $\mathrm{nAChR}$ subtype specificity [36]. Site-specific and subtype-specific inhibition of $\mathrm{nAChR} \alpha 7$ may be able to address the controversial effects of $n A C h R \alpha 7$ on tumor progression in different tissues [37].

\section{Conclusions}

In summary, this study demonstrated that cigarette smoke could induce PD-L1 expression on HBECs through the activation of $\mathrm{nAChR} \alpha 7$ followed by activation of the STAT3 and NRF2 pathways. This study paves the way for further study on the role of specific immune-sensitizers that could aid the therapeutic effects of anti-PD-1 treatment in lung cancer.

Supplementary Materials: The following are available online at https://www.mdpi.com/article/10 .3390/ cancers13215345/s1. Figure S1: Waterfall plot of Cignal 45-pathway reporter array. Figure S2: Uncropped images for all Western blot analysis with the indicated target proteins. 
Author Contributions: Conceptualization, H.-H.K., J.D.M. and D.C.-L.L.; data acquisition, H.-H.K., K.-H.C. and D.C.-L.L.; data analysis and interpretation: H.-H.K., B.G., J.D.M. and D.C.-L.L.; writingoriginal draft preparation, H.-H.K., B.G., K.-H.C., M.S.-M.I., J.D.M. and D.C.-L.L.; writing-review and editing, H.-H.K., B.G., K.-H.C., M.S.-M.I., J.D.M. and D.C.-L.L. All authors have read and agreed to the published version of the manuscript.

Funding: The work was supported in part by the Lee and the Ho Families Respiratory Research Fund, the HKU YC Chan Scientist Award, the Hui Hoy \& Chow Sin Lan Charity Fund Ltd., and the US National Cancer Institute Lung Cancer SPORE P50 CA070907.

Institutional Review Board Statement: All study procedures and establishment of the cell lines were carried out as approved by the Institutional Review Board (IRB) of the University of Hong Kong (HKU)/Hong Kong Hospital Authority Hong Kong West Cluster (HK HA HKWC 09-120), and the research was carried out in accordance with the Declaration of Helsinki (2008).

Informed Consent Statement: Informed consent was obtained from all subjects involved in the study.

Data Availability Statement: The authors declare that the data supporting the findings of this study are available within the article and its supplementary information files.

Acknowledgments: We would like to thank Nerissa Lee and Junyang Deng for all the technical and statistical support provided in this project.

Conflicts of Interest: J.D.M. receives licensing royalties from the US National Institute of Health, and the University of Texas Southwestern Medical Center at Dallas for distribution of human tumor cells and HBEC strains. The other authors declare no conflict of interest.

\section{References}

1. Hecht, S.S. Lung carcinogenesis by tobacco smoke. Int. J. Cancer 2012, 131, 2724-2732. [CrossRef]

2. Khuder, S.A. Effect of cigarette smoking on major histological types of lung cancer: A meta-analysis. Lung Cancer 2001, 31, 139-148. [CrossRef]

3. Hecht, S.S. Biochemistry, biology, and carcinogenicity of tobacco-specific N-nitrosamines. Chem. Res. Toxicol. 1998, 11, 559-603. [CrossRef]

4. Bosse, Y.; Amos, C.I. A Decade of GWAS Results in Lung Cancer. Cancer Epidemiol. Prev. Biomark. 2018, 27, 363-379. [CrossRef]

5. Le Marchand, L.; Derby, K.S.; Murphy, S.E.; Hecht, S.S.; Hatsukami, D.; Carmella, S.G.; Tiirikainen, M.; Wang, H. Smokers with the CHRNA lung cancer-associated variants are exposed to higher levels of nicotine equivalents and a carcinogenic tobacco-specific nitrosamine. Cancer Res. 2008, 68, 9137-9140. [CrossRef] [PubMed]

6. Yang, L.; Lu, X.; Qiu, F.; Fang, W.; Zhang, L.; Huang, D.; Xie, C.; Zhong, N.; Ran, P.; Zhou, Y.; et al. Duplicated copy of CHRNA7 increases risk and worsens prognosis of COPD and lung cancer. Eur. J. Hum. Genet. 2015, 23, 1019-1024. [CrossRef] [PubMed]

7. Lam, D.C.; Luo, S.Y.; Fu, K.H.; Lui, M.M.; Chan, K.H.; Wistuba, I.I.; Gao, B.; Tsao, S.W.; Ip, M.S.; Minna, J.D. Nicotinic acetylcholine receptor expression in human airway correlates with lung function. Am. J. Physiol. Lung Cell Mol. Physiol. 2016, 310, L232-L239. [CrossRef]

8. Gahring, L.C.; Myers, E.J.; Dunn, D.M.; Weiss, R.B.; Rogers, S.W. Lung epithelial response to cigarette smoke and modulation by the nicotinic alpha 7 receptor. PLoS ONE 2017, 12, e0187773. [CrossRef]

9. Mo, J.; Hu, X.; Gu, L.; Chen, B.; Khadaroo, P.A.; Shen, Z.; Dong, L.; Lv, Y.; Chitumba, M.N.; Liu, J. Smokers or non-smokers: Who benefits more from immune checkpoint inhibitors in treatment of malignancies? An up-to-date meta-analysis. World J. Surg. Oncol. 2020, 18, 15. [CrossRef] [PubMed]

10. Davis, A.A.; Chae, Y.K.; Agte, S.; Pan, A.; Mohindra, N.A.; Villaflor, V.M.; Giles, F.J. Association of tumor mutational burden with smoking and mutation status in non-small cell lung cancer (NSCLC). J. Clin. Oncol. 2017, 35, 24. [CrossRef]

11. Norum, J.; Nieder, C. Tobacco smoking and cessation and PD-L1 inhibitors in non-small cell lung cancer (NSCLC): A review of the literature. ESMO Open 2018, 3, e000406. [CrossRef]

12. Suresh, S.; Chen, B.; Zhu, J.; Golden, R.J.; Lu, C.; Evers, B.M.; Novaresi, N.; Smith, B.; Zhan, X.; Schmid, V.; et al. elF5B drives integrated stress response-dependent translation of PD-L1 in lung cancer. Nat. Cancer 2020, 1, 533-545. [CrossRef] [PubMed]

13. Sato, M.; Shay, J.W.; Minna, J.D. Immortalized normal human lung epithelial cell models for studying lung cancer biology. Respir. Investig. 2020, 58, 344-354. [CrossRef]

14. Cai, L.; Lin, S.; Girard, L.; Zhou, Y.; Yang, L.; Ci, B.; Zhou, Q.; Luo, D.; Yao, B.; Tang, H.; et al. LCE: An open web portal to explore gene expression and clinical associations in lung cancer. Oncogene 2019, 38, 2551-2564. [CrossRef]

15. Chandrashekar, D.S.; Bashel, B.; Balasubramanya, S.A.H.; Creighton, C.J.; Ponce-Rodriguez, I.; Chakravarthi, B.; Varambally, S. UALCAN: A Portal for Facilitating Tumor Subgroup Gene Expression and Survival Analyses. Neoplasia 2017, 19, 649-658. [CrossRef] 
16. Ramirez, R.D.; Sheridan, S.; Girard, L.; Sato, M.; Kim, Y.; Pollack, J.; Peyton, M.; Zou, Y.; Kurie, J.M.; Dimaio, J.M.; et al. Immortalization of human bronchial epithelial cells in the absence of viral oncoproteins. Cancer Res. 2004, 64, 9027-9034. [CrossRef] [PubMed]

17. Thai, P.; Statt, S.; Chen, C.H.; Liang, E.; Campbell, C.; Wu, R. Characterization of a Novel Long Noncoding RNA, SCAL1, Induced by Cigarette Smoke and Elevated in Lung Cancer Cell Lines. Am. J. Respir. Cell Mol. Biol. 2013, 49, 204-211. [CrossRef]

18. Boo, H.-J.; Min, H.-Y.; Jang, H.-J.; Yun, H.J.; Smith, J.K.; Jin, Q.; Lee, H.-J.; Liu, D.; Kweon, H.-S.; Behrens, C.; et al. The tobacco-specific carcinogen-operated calcium channel promotes lung tumorigenesis via IGF2 exocytosis in lung epithelial cells. Nat. Commun. 2016, 7, 12961. [CrossRef] [PubMed]

19. Lam, D.C.; Kwok, H.H.; Yu, W.C.; Ko, F.W.; Tam, C.Y.; Lau, A.C.; Fong, D.Y.; Ip, M.S. CC16 levels correlate with cigarette smoke exposure in bronchial epithelial cells and with lung function decline in smokers. BMC Pulm. Med. 2018, 18, 47. [CrossRef]

20. Solis, L.M.; Behrens, C.; Dong, W.; Suraokar, M.; Ozburn, N.C.; Moran, C.A.; Corvalan, A.H.; Biswal, S.; Swisher, S.G.; Bekele, B.N.; et al. Nrf2 and Keap1 abnormalities in non-small cell lung carcinoma and association with clinicopathologic features. Clin. Cancer Res. 2010, 16, 3743-3753. [CrossRef]

21. DeNicola, G.M.; Karreth, F.A.; Humpton, T.J.; Gopinathan, A.; Wei, C.; Frese, K.; Mangal, D.; Yu, K.H.; Yeo, C.J.; Calhoun, E.S.; et al. Oncogene-induced Nrf2 transcription promotes ROS detoxification and tumorigenesis. Nature 2011, 475, 106-109. [CrossRef]

22. Pfeifer, G.P.; Denissenko, M.F.; Olivier, M.; Tretyakova, N.; Hecht, S.S.; Hainaut, P. Tobacco smoke carcinogens, DNA damage and p53 mutations in smoking-associated cancers. Oncogene 2002, 21, 7435-7451. [CrossRef]

23. Krysan, K.; Tran, L.M.; Grimes, B.S.; Fishbein, G.A.; Seki, A.; Gardner, B.K.; Walser, T.C.; Salehi-Rad, R.; Yanagawa, J.; Lee, J.M.; et al. The Immune Contexture Associates with the Genomic Landscape in Lung Adenomatous Premalignancy. Cancer Res. 2019, 79, 5022-5033. [CrossRef]

24. Dave, K.; Ali, A.; Magalhaes, M. Increased expression of PD-1 and PD-L1 in oral lesions progressing to oral squamous cell carcinoma: A pilot study. Sci. Rep. 2020, 10, 9705. [CrossRef]

25. Wang, J.; Xie, T.; Wang, B.; William, W.N.; Heymach, J.V.; El-Naggar, A.K.; Myers, J.N.; Caulin, C. PD-1 Blockade Prevents the Development and Progression of Carcinogen-Induced Oral Premalignant Lesions. Cancer Prev. Res. 2017, 10, 684-693. [CrossRef] [PubMed]

26. Sinkus, M.L.; Graw, S.; Freedman, R.; Ross, R.G.; Lester, H.A.; Leonard, S. The human CHRNA7 and CHRFAM7A genes: A review of the genetics, regulation, and function. Neuropharmacology 2015, 96, 274-288. [CrossRef] [PubMed]

27. Russo, P.; Bonassi, S.; Giacconi, R.; Malavolta, M.; Tomino, C.; Maggi, F. COVID-19 and smoking: Is nicotine the hidden link? Eur. Respir. J. 2020, 55, 2001116. [CrossRef]

28. Olds, J.L.; Kabbani, N. Is nicotine exposure linked to cardiopulmonary vulnerability to COVID-19 in the general population? FEBS J. 2020, 287, 3651-3655. [CrossRef]

29. Wang, S.; Hu, Y. $\alpha 7$ nicotinic acetylcholine receptors in lung cancer. Oncol. Lett. 2018, 16, 1375-1382. [CrossRef] [PubMed]

30. Nguyen, H.D.; Liao, Y.C.; Ho, Y.S.; Chen, L.C.; Chang, H.W.; Cheng, T.C.; Liu, D.; Lee, W.R.; Shen, S.C.; Wu, C.H.; et al. The $\alpha 9$ Nicotinic Acetylcholine Receptor Mediates Nicotine-Induced PD-L1 Expression and Regulates Melanoma Cell Proliferation and Migration. Cancers 2019, 11, 1991. [CrossRef]

31. Garcia-Diaz, A.; Shin, D.S.; Moreno, B.H.; Saco, J.; Escuin-Ordinas, H.; Rodriguez, G.A.; Zaretsky, J.M.; Sun, L.; Hugo, W.; Wang, X.; et al. Interferon Receptor Signaling Pathways Regulating PD-L1 and PD-L2 Expression. Cell Rep. 2017, 19, 1189-1201. [CrossRef] [PubMed]

32. Zhu, B.; Tang, L.; Chen, S.; Yin, C.; Peng, S.; Li, X.; Liu, T.; Liu, W.; Han, C.; Stawski, L.; et al. Targeting the upstream transcriptional activator of PD-L1 as an alternative strategy in melanoma therapy. Oncogene 2018, 37, 4941-4954. [CrossRef]

33. Best, S.A.; De Souza, D.P.; Kersbergen, A.; Policheni, A.N.; Dayalan, S.; Tull, D.; Rathi, V.; Gray, D.H.; Ritchie, M.E.; McConville, M.J.; et al. Synergy between the KEAP1/NRF2 and PI3K Pathways Drives Non-Small-Cell Lung Cancer with an Altered Immune Microenvironment. Cell Metab. 2018, 27, 935-943.e4. [CrossRef] [PubMed]

34. Wang, G.-Z.; Zhang, L.; Zhao, X.-C.; Gao, S.-H.; Qu, L.-W.; Yu, H.; Fang, W.-F.; Zhou, Y.-C.; Liang, F.; Zhang, C.; et al. The Aryl hydrocarbon receptor mediates tobacco-induced PD-L1 expression and is associated with response to immunotherapy. Nat. Commun. 2019, 10, 1125. [CrossRef] [PubMed]

35. Desrichard, A.; Kuo, F.; Chowell, D.; Lee, K.-W.; Riaz, N.; Wong, R.J.; Chan, T.A.; Morris, L.G.T. Tobacco Smoking-Associated Alterations in the Immune Microenvironment of Squamous Cell Carcinomas. J. Natl. Cancer Inst. 2018, 110, 1386-1392. [CrossRef]

36. Wu, C.-H.; Lee, C.-H.; Ho, Y.-S. Nicotinic Acetylcholine Receptor-Based Blockade: Applications of Molecular Targets for Cancer Therapy. Clin. Cancer Res. 2011, 17, 3533-3541. [CrossRef] [PubMed]

37. Hajiasgharzadeh, K.; Somi, M.H.; Sadigh-Eteghad, S.; Mokhtarzadeh, A.; Shanehbandi, D.; Mansoori, B.; Mohammadi, A.; Doustvandi, M.A.; Baradaran, B. The dual role of alpha7 nicotinic acetylcholine receptor in inflammation-associated gastrointestinal cancers. Heliyon 2020, 6, e03611. [CrossRef] [PubMed] 